Molecules 2001, 6, 406-416

\title{
molecules
}

ISSN 1420-3049

http://www.mdpi.org

\section{Bis-Porphyrin Racks with Space-Separated Co-Planar Porphyrin Rings}

\section{Martin R. Johnston*}

Centre for Molecular Architecture, Central Queensland University, Rockhampton, Queensland, Australia, 4702.

*To whom correspondence should be addressed; e-mail: $\underline{\text { m.johnston@equ.edu.au }}$

Received: 7 December 2000; in revised form 19 March 2001 / Accepted: 21 March 2001 / Published: 31 March 2001

\begin{abstract}
A porphyrin appended norbornenyl building block $\mathbf{8}$ has been isolated and coupled, using a 1,3-dipolar ACE reaction, to yield bis-porphyrin compounds in which the porphyrin moietes are angled upward relative to the norbornane backbone.
\end{abstract}

Keywords: porphyrin building block, dipolar coupling, bis-porphyrins.

\section{Introduction}

Following the elucidation of the strict geometric alignment of chromophores within purple photosynthetic bacteria [1], numerous reports have appeared in the literature regarding approaches to the construction of multiporphyrinic arrays, with a view to mimicking the natural system as a light harvesting machine. Initially, these reports involved the covalent attachment of chromophores [2], however recent efforts in this field have increasingly taken advantage of self-assembly strategies for array construction [3].

The design of new molecular architectures for bis-porphyrins and their use in a fundamental study of self-assembly processes has been an active goal of our recent research [4,5]. In earlier papers, we concentrated on the synthesis of $\mathrm{V}$ - and U-shaped cavities with the porphyrin macrocycle attached in a fixed geometry by two bonds to the termini of fused carbocyclic frames. Two elements dominate the shape of such systems: a) the topology of the carbocyclic frame and b) the angle of attachment of the 
porphyrin ring to the frame. In a preliminary communication on this work [6], we enunciated the use of angled norbornene blocks which carry the porphyrin ring and showed how the topology of the frame could be used to achieve specific geometric outcomes. Implicit in the success of the approach, was the ability to make the angled blocks and to construct the molecular frame with predefined stereochemistry. We found that 1,3-dipolar ACE coupling [7] of cyclobutene epoxides with norbornenes has satisfied the latter requirement and the same reaction protocol is exploited in the present study.

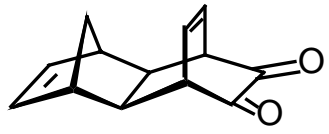

1

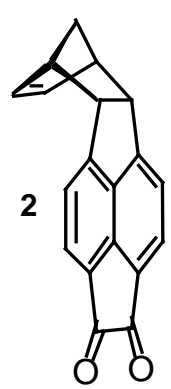

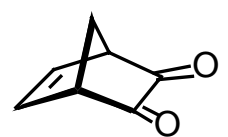

3

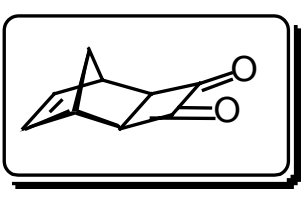

4

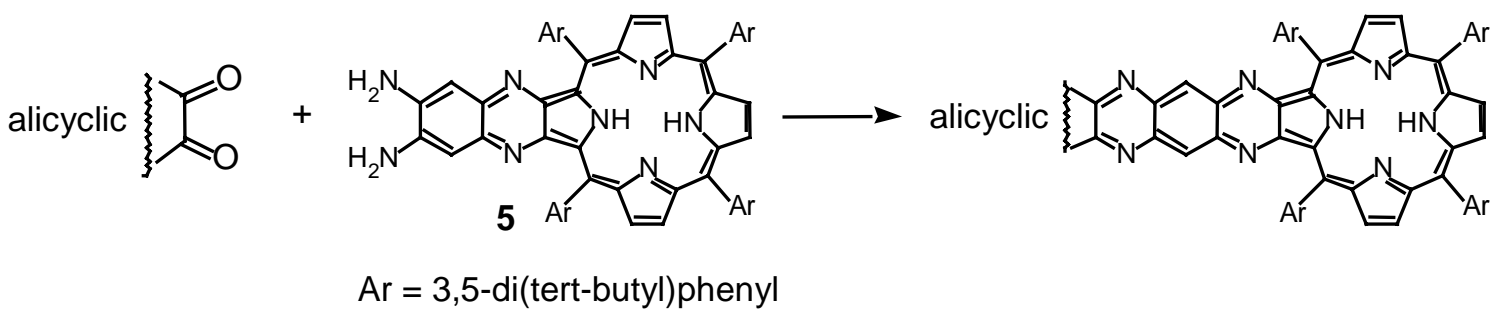

Scheme 1: Various norbornenyl $\alpha$-diones 1-4 used to produce porphyrin blocks via condensation with diamine 5.

The norbornene blocks have been functionalised by condensation of norbornene-containing alicyclic $\alpha$-diones with the Crossley porphyrin diamine 5 [8]. The $\alpha$ - diones 1 [4,6], 2 [6] and 3 [9] used in our earlier work have a geometry in which the $\alpha$-dione component bears a downward relationship to the norbornene frame that is accentuated following condensation with the porphyrin. Such a geometry is well suited for the construction of $\mathrm{U}$ - and V-shaped bis-porphyrins as the molecular frame is curved downwards and helps position the porphyrins on the underside of the frame ("southern" systems; substituents on these systems have been designated either "northern" or "southern" depending on their relative orientation to the methano-bridges of the polynorbornane backbone [10]).

In this paper we discuss the preparation and use of a porphyrin block derived from the upwarddirected $\alpha$-dione 4. Our new objective has been to use this block to prepare "northern" V-shaped systems by coupling with frames of linear geometry and co-planar bis-porphyrins by reaction with curved [n]polynorbornane frames.

\section{Results and Discussion}

The required $\alpha$-dione 4 is a known compound and was prepared following the method reported by Martin et al. [11] (Scheme 2a). Condensation of 4 with the Crossley diamine 5 [8] produced the porphyrin block $\mathbf{8}$ (Scheme $2 \mathrm{~b}$ ) that was characterised by spectroscopy and high resolution electrospray 
mass spectrometry (HR-ESMS) (found $m / z$ 1307.8294). The ${ }^{1} \mathrm{H}-\mathrm{NMR}$ spectrum of 8 (Figure 1 ) is typical for porphyrin-appended norbornene blocks with the porphyrin and alicyclic resonances well separated.

a) Synthesis of $\alpha$-dione 4

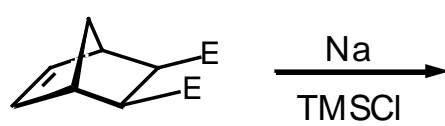

6

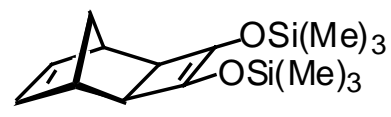

7

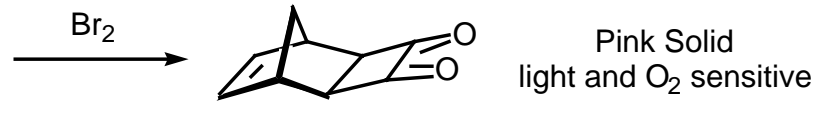

4

b) Preparation of Porphyrin block 8

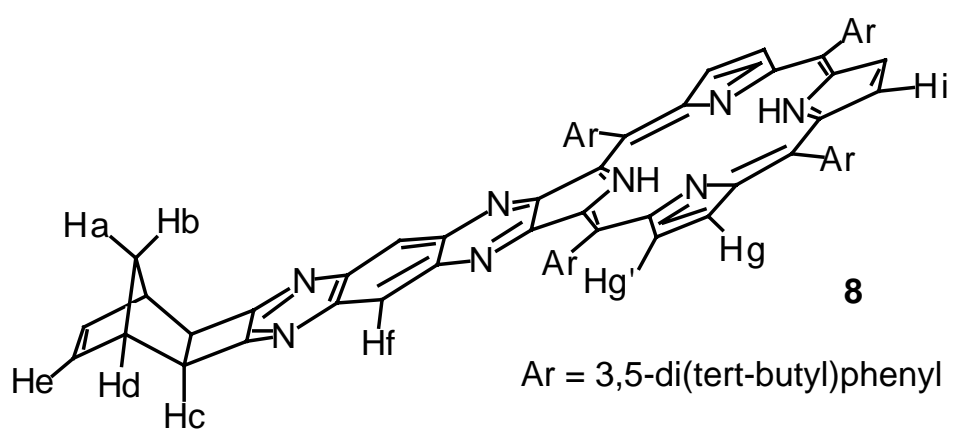

Scheme 2: Synthetic methodologies for isolation of dione $\mathbf{4}$ and porphyrin block 8 .

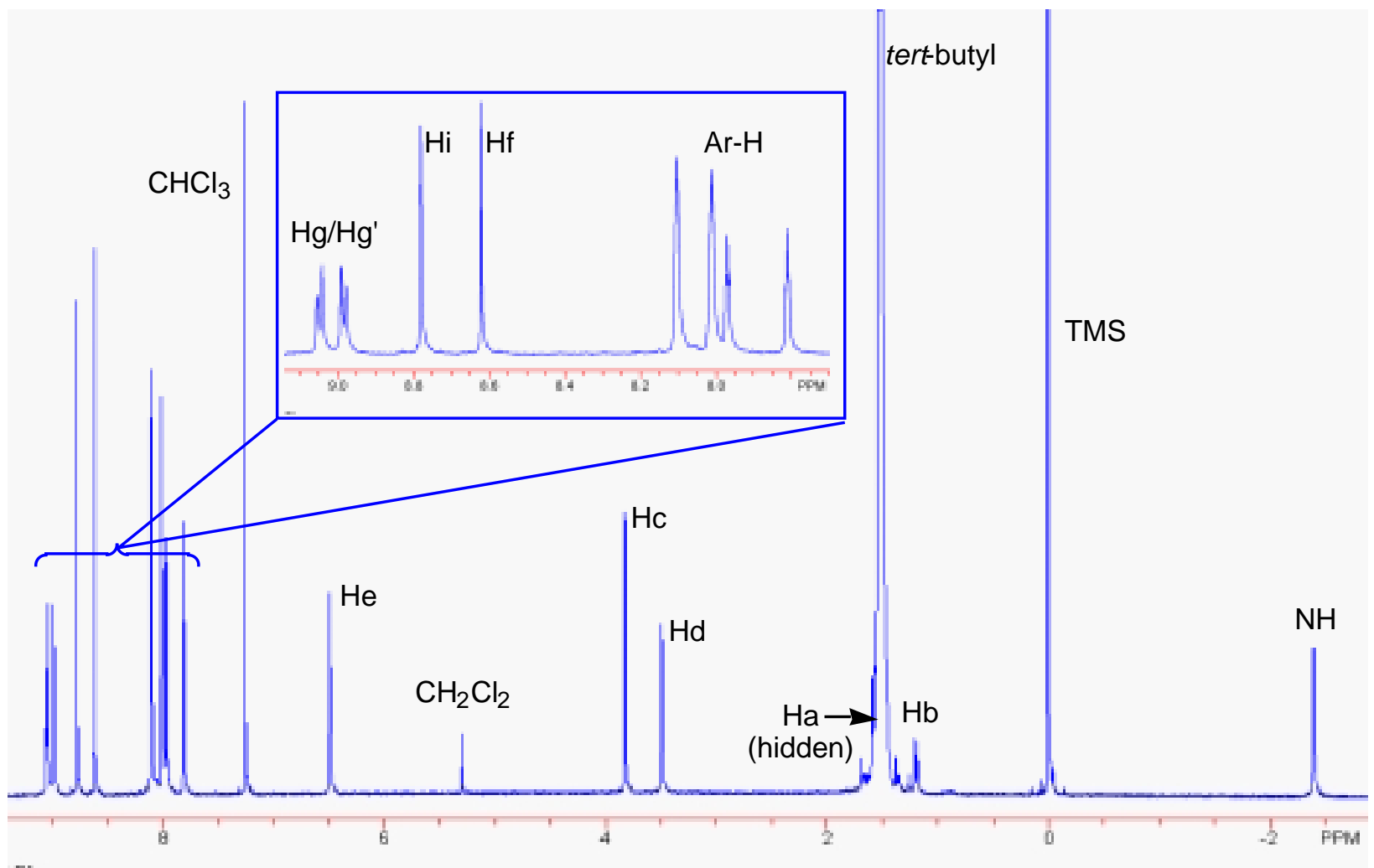

Figure 1: ${ }^{1} \mathrm{H}-\mathrm{NMR}$ spectrum $\left(300 \mathrm{MHz}, \mathrm{CDCl}_{3}\right)$ of porphyrin block $\mathbf{8}$. 
The porphyrin resonances, because of the Cs symmetry of $\mathbf{8}$, occur as a two doublets for $\mathrm{Hg}$ and $\mathrm{Hg}^{\prime}$ $(\delta 9.04,8.96)$ and singlets for $\mathrm{Hi}(\delta 8.78)$ and the tetrazaanthrancene protons Hf $(\delta 8.62)$. The aryl protons resonate as two sets (ratio 2:1) reflecting the 3,5-substitution pattern of the aryl ring $(\delta 8.10-$ 7.81). The inner NH protons resonate at $\delta-2.39$ as expected due to the large paramagnetic ring current present in the porphyrin macrocycle. The tert-butyl groups present in 8 resonate at $\delta 1.50-1.53$ and, in chloroform solution, these resonances overlap with the methano-bridge proton Ha resonance. The presence of the Ha proton resonance was detected by a COSY experiment. The resonance for the vinyl protons (He) occurred as a singlet at $\delta 6.49$ and its presence was used to monitor the progress of the ACE coupling reaction. Typically, protons Hd (allylic) and Hc (benzylic) occur downfield owing to the strong electron-withdrawing effect of the azaheterocycle, accounting for the lower field shift of Hc relative to $\mathrm{Hd}$. The broadening of the latter signal is due to coupling with the methano-bridge protons. Molecular modeling [12] of 8 was carried out at the semi-empirical level of theory (AM1) and revealed the overall shape of the block (Figure 2). The porphyrin macrocyclic ring is angled upward from the norbornene skeleton at an angle of $28^{\circ}$ and thereby contrasts with the previously prepared blocks $\mathbf{1}-\mathbf{3}$.

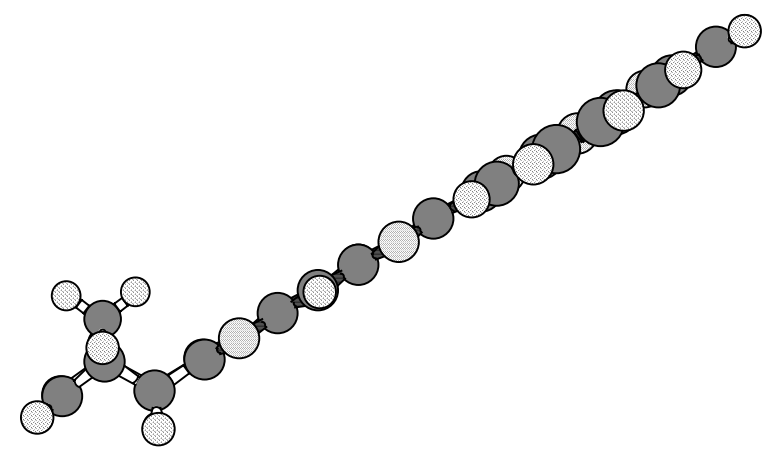

Figure 2: Molecular modeling (AM1) of the porphyrin block $\mathbf{8}$.

Several coupling reactions were investigated utilising block 8 to produce bis-porphyrin compounds. The coupling reactions were based on the ACE coupling protocol which utilises a 1,3-dipolar cycloaddition strategy in which the dipole is generated in situ by ring opening of an epoxide and trapped by the norbornene. In this work, bis-epoxide molecules $\mathbf{9 ,} \mathbf{1 1}$ and $\mathbf{1 3}$ were used to yield products of differing geometries due to the different spatial requirements of the bis-epoxide spacer backbone.

In the first instance, bis-epoxide 9 was heated in a sealed tube with block $\mathbf{8}$ (Scheme 3) at $140^{\circ} \mathrm{C}$ for three days to yield the bis-porphyrin 10, which was isolated by chromatographic separation. Once again bis-porphyrin $\mathbf{1 0}$ was characterised by ${ }^{1} \mathrm{H}$ NMR spectroscopy (Figure 3) and HR-ESMS with proton resonances being assigned using a combination of 2D COSY and NOESY experiments (in the NOESY spectrum of 10, in addition to the expected intramolecular signals, several additional cross peaks were observed and which were found to be concentration dependant, however, the ${ }^{1} \mathrm{H}-\mathrm{NMR}$ spectrum of $\mathbf{1 0}$ showed no concentration dependant shifts and we are currently investigating this phenomena; a referee is thanked for bringing this to the author's attention).

The proton resonances for the porphyrin moiety are little changed from those observed in $\mathbf{8}$ except for the alicyclic backbone. The olefinic proton resonance (He) present in block $\mathbf{8}$ is lost upon coupling, being shifted upfield to $\delta 2.28$ in line with the change in hybridisation. 


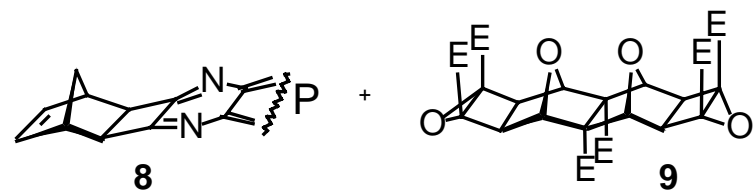

$140^{\circ} \mathrm{C}, 3$ days, $\mathrm{THF}$ quantitative
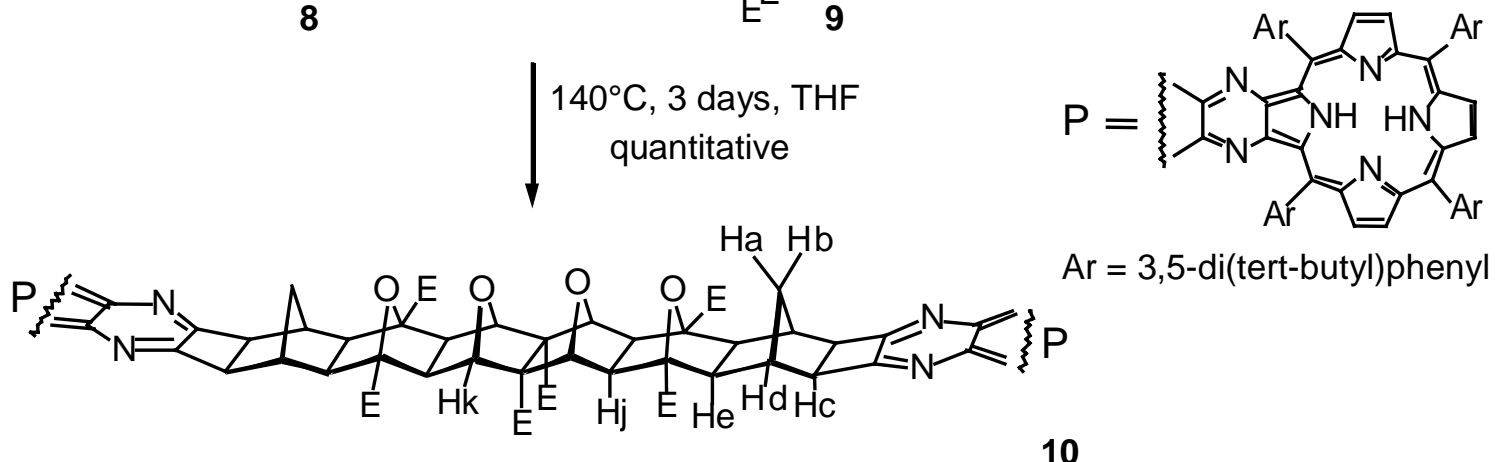

10

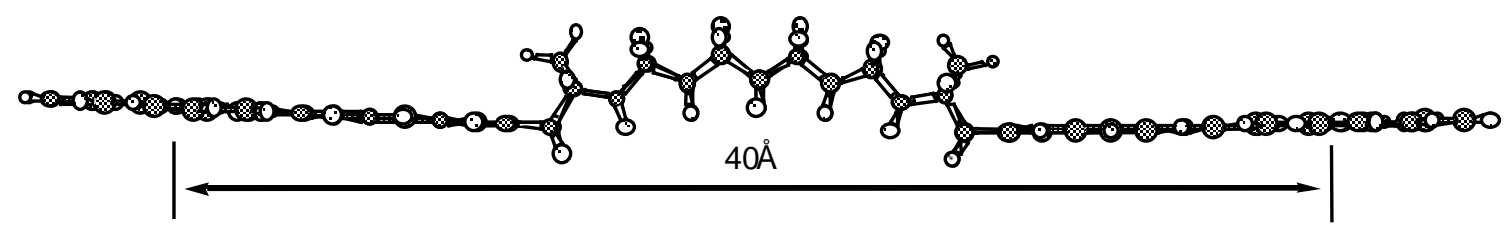

Scheme 3: Synthesis of bis-porphyrin 10 using porphyrin block 8 and bis-epoxide 9.

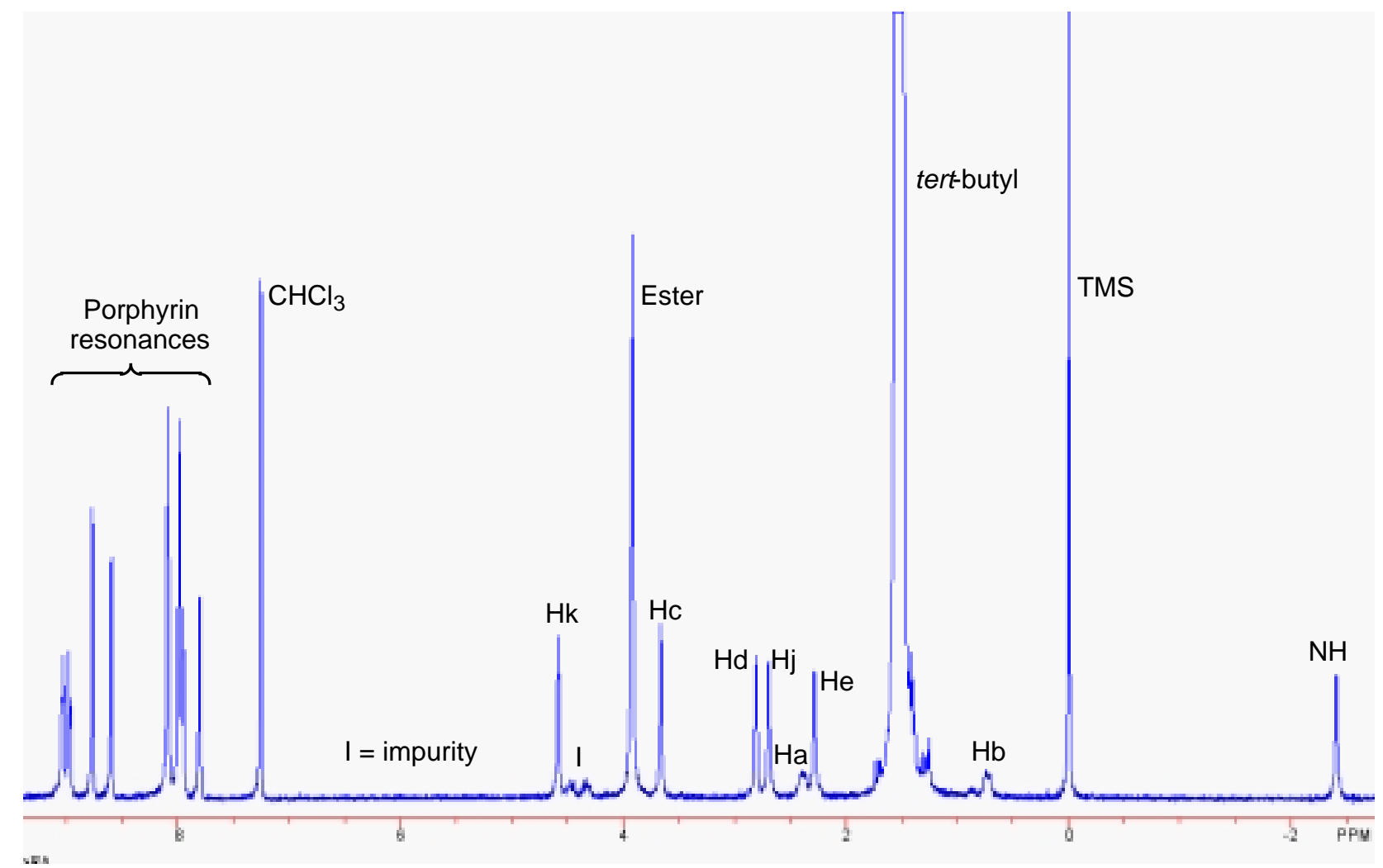

Figure 3: ${ }^{1} \mathrm{H}$ NMR spectrum $\left(300 \mathrm{MHz}, \mathrm{CDCl}_{3}\right)$ of bis-porphyrin cavity $\mathbf{1 0}$. 
Further, the new resonances for methylene protons $\mathrm{Ha}$ and $\mathrm{Hb}$ are diagnostic $(\delta 2.40$ and 0.72$)$ since Ha is significantly downfield shifted being influenced by the adjacent 7-oxanorbornane system. Such a shift reinforces the linear nature of the coupled product. HR-ESMS yielded a doubly charged molecular ion at the required position $(\mathrm{m} / \mathrm{z}$ 1605.896). Molecular modeling (AM1) reveals the almost coplanarity of the porphyrin macrocycles within 10, with each porphyrin plane approximately $2.5^{\circ}$ from the horizontal, with an interporphyrin centre-to-centre distance of $40 \AA$.

Heating of 8 and 11 in a sealed tube (THF, $140^{\circ} \mathrm{C}, 2$ days) produced the bis-porphyrin 12 in $34 \%$ yield after chromatographic purification (Scheme 4). Product identification was confirmed by ${ }^{1} \mathrm{H}-\mathrm{NMR}$ spectroscopy (Figure 4) and HR-ESMS.

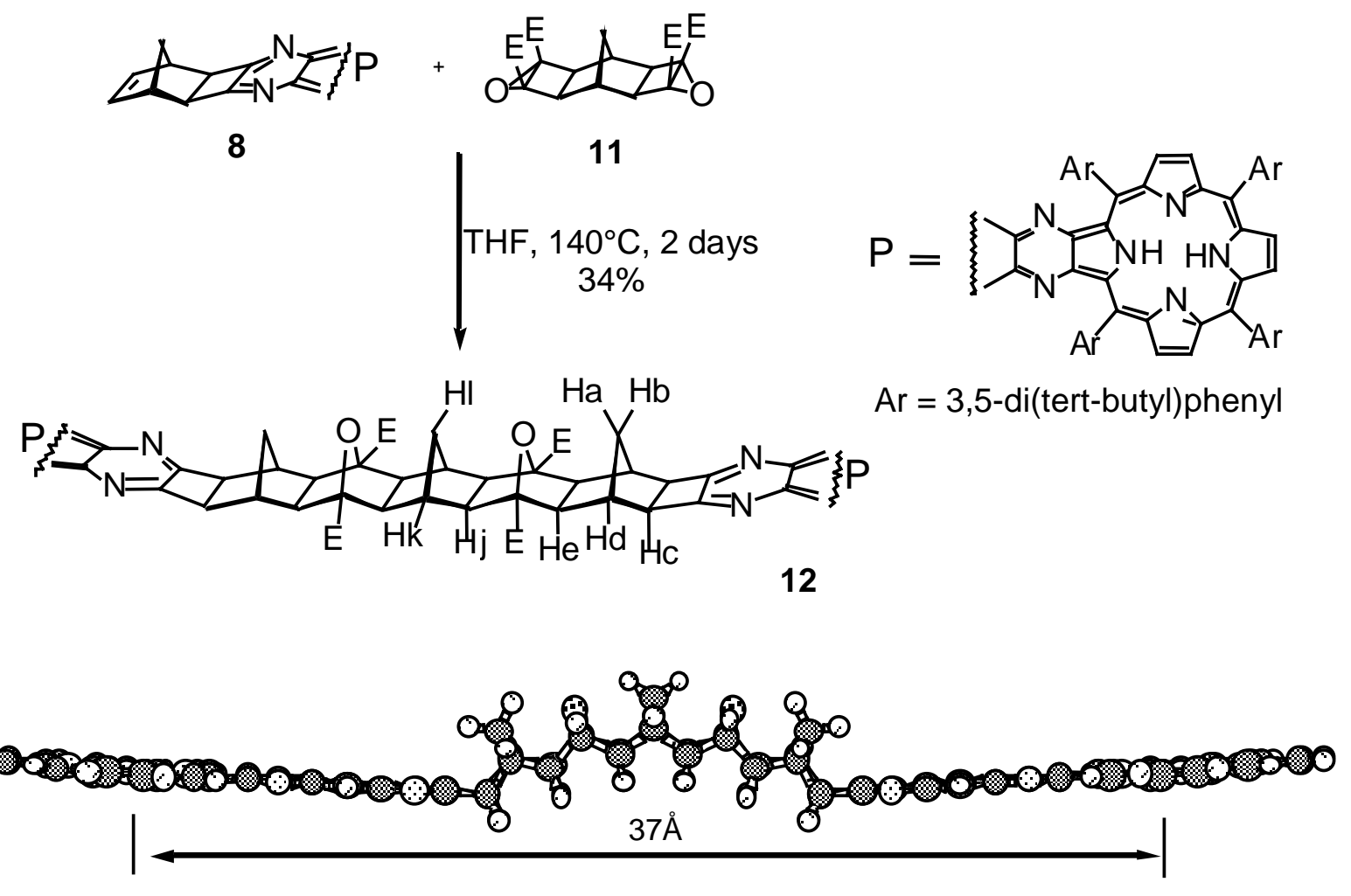

Scheme 4: Synthetic scheme outlining the isolation of bis-porphyrin 12.

In a similar manner to $\mathbf{1 0}$, the ${ }^{1} \mathrm{H}-\mathrm{NMR}$ resonances for protons attached to the porphyrin moiety are little affected by the coupling process, yet major changes are observed for the alicyclic backbone proton $\mathrm{Ha}, \mathrm{Hb}$, and $\mathrm{He}$ resonances. The Ha resonance is influenced by the adjacent 7-oxanorbornane ring and is shifted downfield to $\delta 2.28$, whereas $\mathrm{Hb}$ is shifted upfield to $\delta 0.71$. The resonance for He is shifted upfield concomitant with the loss of olefinic character as a result of the coupling reaction. The resonances at $\delta 2.04$ and $\delta 2.28$ represent overlapping signals from several protons and this complication prevents the exact identification of the proton resonances (Figure 4). HR-ESMS again supported the identity of $\mathbf{1 2}$ with a doubly charged molecular ion being observed $(\mathrm{m} / \mathrm{z}$ 1512.889).

Molecular modeling (AM1) of 12 (Scheme 4) again reveals the near coplanarity of the porphyrin macrocycles within 12, with each porphyrin plane inclined only $4^{\circ}$ from the horizontal. The interporphyrin centre-to-centre distance, in this case, was calculated to be $37 \AA$. 


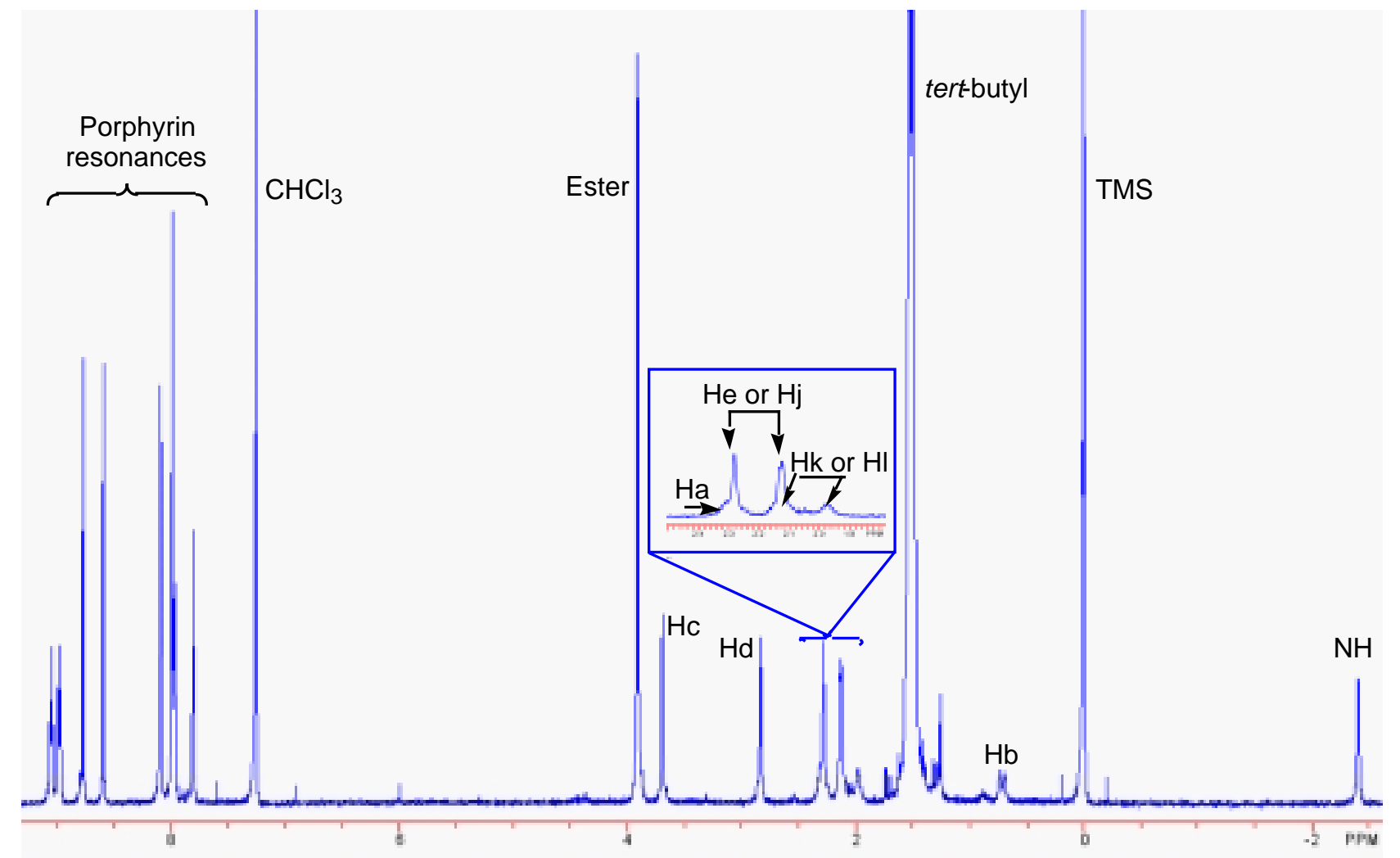

Figure 4: ${ }^{1} \mathrm{H}-\mathrm{NMR}$ spectrum $\left(300 \mathrm{MHz}, \mathrm{CDCl}_{3}\right)$ of bis-porphyrin cavity 12.

Porphyrin block 8 and bis-epoxide 13 were heated in sealed tube at $160^{\circ} \mathrm{C}$ for 2 days and yielded 14 in good yield (62\%) (Scheme 5). ${ }^{1} \mathrm{H}-\mathrm{NMR}$ resonances were again assigned using a combination of 2DCOSY and NOESY experiments and are shown in Figure 5.

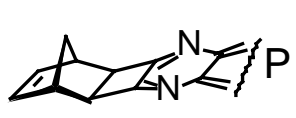

8

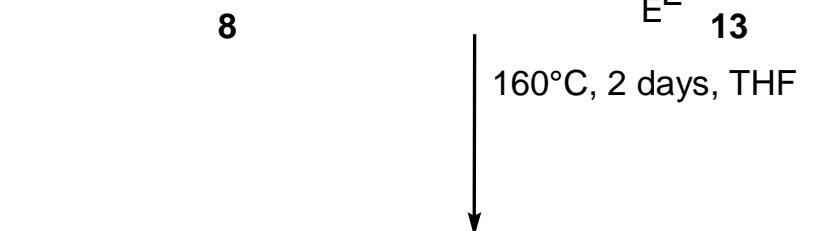

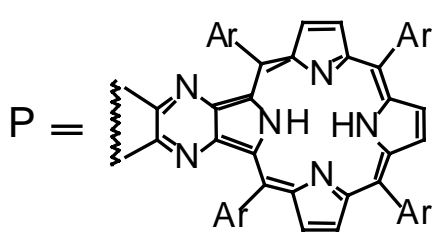

$\mathrm{Ar}=3,5-\mathrm{di}($ tert-butyl)phenyl
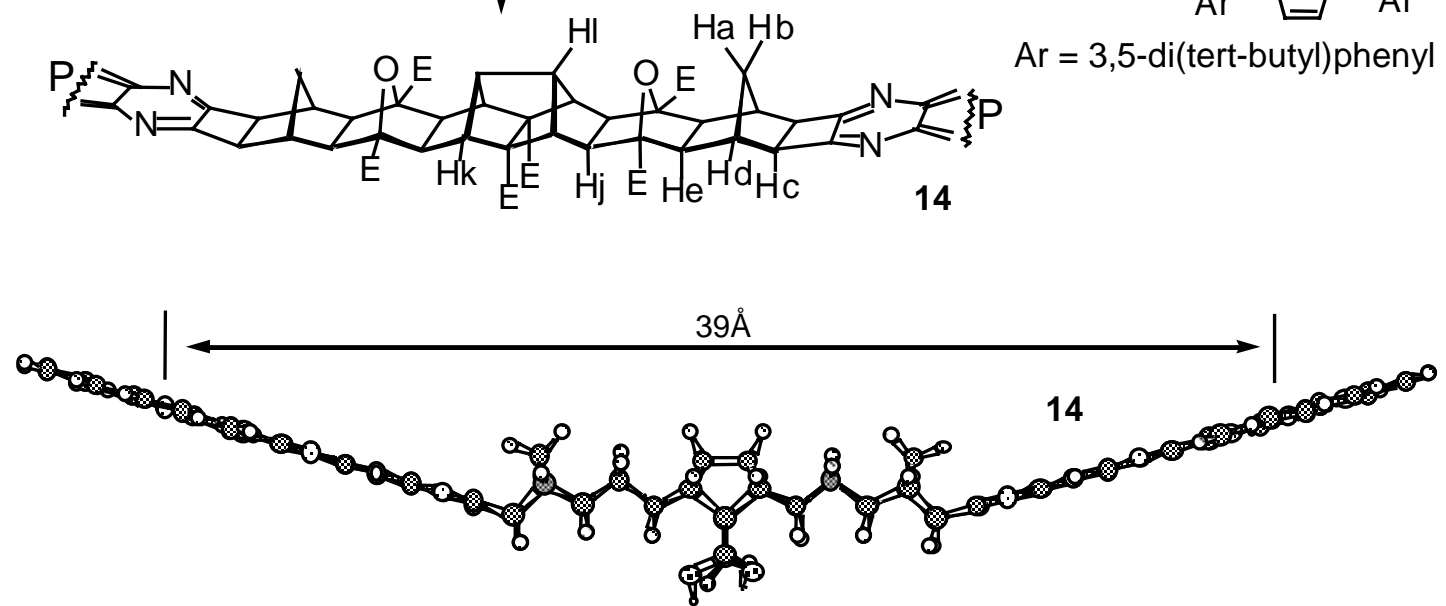

Scheme 5: Synthesis of bis-porphyrin 14 from porphyrin block 8 and bis-epoxide 13. 


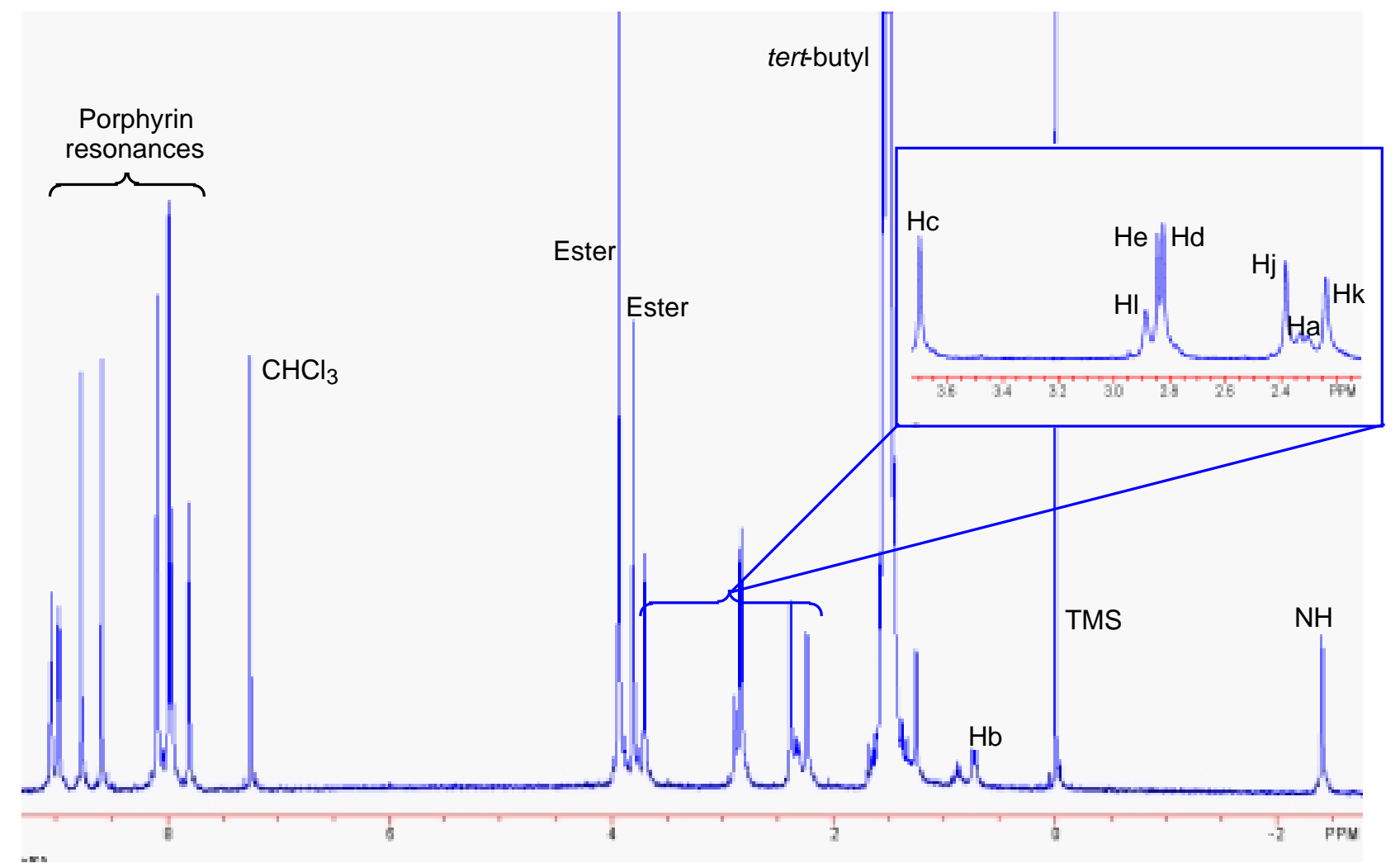

Figure 5: ${ }^{1} \mathrm{H}-\mathrm{NMR}$ spectrum $\left(300 \mathrm{MHz}, \mathrm{CDCl}_{3}\right)$ of bis-porphyrin cavity 14.

Characteristic ${ }^{1} \mathrm{H}-\mathrm{NMR}$ resonances were again observed for $\mathrm{Ha}\left(\begin{array}{ll}\delta & 2.32\end{array}\right)$ and $\mathrm{Hb}\left(\begin{array}{ll}\delta & 0.72\end{array}\right)$ and supported the linear geometry for the coupling protocol. The structure of $\mathbf{1 4}$ was further supported by the presence of a doubly charged molecular ion observed at $m / z 1602.9084$ in the HR-ESMS.

Molecular modeling (AM1) of $\mathbf{1 4}$ (Scheme 5) revealed that each porphyrin plane is tilted upwards from coplananity by $17^{\circ}$. Compound 14 represents the first example of a bis-porphyrin cavity in which the porphyrin macrocycle is directed upwards relative to the connecting alicyclic backbone. The interporphyrin centre-to-centre separation within $\mathbf{1 4}$ was calculated to be $39 \AA$.

\section{Conclusions}

Having successfully isolated 10, 11 and 12, current attention is being directed at the examination of the coordination chemistry of their metallated porphyrin derivatives and their ability to coordinate bidentate ligands. In particular, the assembly of the bis-porphyrin molecules to create larger supramolecular arrays will be targeted in an attempt to mimic the arrangement of photochromic pigments found in the natural photosynthetic apparatus. The results of these studies will be reported in due course.

\section{Acknowledgements}

The author is grateful to CQU for the provision of a Research Advancement Award 1999-2001 and the CMA for providing research facilities and a professional research environment in which to work. 


\section{Experimental}

\section{General}

All solvents were used as supplied with the exception of THF (distilled from $\mathrm{Na}$ /Benzophenone) and pyridine (distilled from $\mathrm{KOH}$ and stored over molecular sieves). Melting points were determined using GALLENKAMP melting point apparatus and are uncorrected. Thin layer chromatography was performed on pre-coated aluminium sheets on Merck silica gel $60 \mathrm{~F}_{254}$ and visualised using visible or UV light (254 and $365 \mathrm{~nm}$ ). Column chromatography was carried out under a positive pressure of air using Merck silica gel (230-400 mesh).

NMR spectra were acquired on either a Bruker AMX300 $(300 \mathrm{MHz})$ or Bruker DRX400 $(400 \mathrm{MHz})$ using standard Bruker pulse programs. Unless otherwise stated, spectra were recorded at $303 \mathrm{~K}$ using deuterated $\mathrm{CHCl}_{3}$ as the solvent with tetramethylsilane (TMS) as an internal standard. Chemical shifts $(\delta)$ are reported as parts per million ( $\mathrm{ppm}$ ) with respect to TMS. Abbreviations used in assigning spectra include: s, singlet; bs, broad singlet; $d$, doublet; $t$, triplet; q, quartet; and m, multiplet. Mass spectra (MS) were analysed on Micromass Mass Spectrometer using electrospray (ES) techniques. Bisepoxides 9[13], 11[14], and 13[15] were kindly supplied by Dr Davor Margetic (CMA).

Porphyrin block 8: Porphyrin diamine $5(0.45 \mathrm{~g}, 0.37 \mathrm{mmol})$ was dissolved in dry, deoxygenated pyridine $(4 \mathrm{~mL})$ along with dione $4(150 \mathrm{mg}, 1 \mathrm{mmol})$ and the solution stirred at ambient temperature under nitrogen in the dark for 2 days. The pyridine was removed under vacuum and the residual solids purified by column chromatography (silica) eluting with dichloromethane (DCM)/petroleum spirit (1:4) to give $8(0.32 \mathrm{~g}, 65 \%)$. M.p. $>350^{\circ} \mathrm{C}$. HR-ESMS calculated for $\mathrm{C}_{91} \mathrm{H}_{102} \mathrm{~N}_{8}(\mathrm{M}+\mathrm{H})^{+} 1307.8305$; observed 1307.8294; ${ }^{1} \mathrm{H}-\mathrm{NMR}\left(\mathrm{CDCl}_{3}\right): \delta-2.39(2 \mathrm{H}, \mathrm{bs}) ; 1.19(1 \mathrm{H}, \mathrm{d}, \mathrm{J}=9.4 \mathrm{~Hz}) ; 1.50-1.53(72 \mathrm{H}, \mathrm{m})$; $1.60(1 \mathrm{H}, \mathrm{d}, \mathrm{J}=9.4 \mathrm{~Hz}$, hidden); $3.49(2 \mathrm{H}, \mathrm{s}) ; 3.82(2 \mathrm{H}, \mathrm{s}) ; 6.49(2 \mathrm{H}, \mathrm{s}) ; 7.81(2 \mathrm{H}, \mathrm{t}, \mathrm{J}=1.4 \mathrm{~Hz}) ; 7.97$ $(2 \mathrm{H}, \mathrm{t}, \mathrm{J}=1.4 \mathrm{~Hz}) ; 8.01(4 \mathrm{H}, \mathrm{d}, \mathrm{J}=1.4 \mathrm{~Hz}) ; 8.10(4 \mathrm{H}, \mathrm{s}) ; 8.62(2 \mathrm{H}, \mathrm{s}) ; 8.78(2 \mathrm{H}, \mathrm{s}) ; 8.96(2 \mathrm{H}, \mathrm{d}, \mathrm{J}=4.8$ $\mathrm{Hz}) ; 9.04(2 \mathrm{H}, \mathrm{d}, \mathrm{J}=4.8 \mathrm{~Hz})$.

Bis-porphyrin adduct 10: Porphyrin block 8 (105 mg, $80 \mu \mathrm{mol})$ was dissolved in THF (1 mL) along with bis-epoxide $9(23 \mathrm{mg}, 38 \mu \mathrm{mol})$ and the solution heated in sealed tube at $140^{\circ} \mathrm{C}$ for 3 days. The material was taken to dryness and purified by column chromatography (silica) eluting with $\mathrm{CHCl}_{3}$ which gave $\mathbf{1 0}$ as a purple solid (112 mg, quantitative yieldbased on block consumed). Recrystalised from DCM/MeOH. M.p. $>350^{\circ} \mathrm{C}$. HR-ESMS calculated for $\mathrm{C}_{208} \mathrm{H}_{230} \mathrm{~N}_{16} \mathrm{O}_{16}(\mathrm{M}+2 \mathrm{H})^{2+} 1605.895$; observed 1605.896;1 ${ }^{1} \mathrm{H}-\mathrm{NMR}\left(\mathrm{CDCl}_{3}\right): \delta-2.40(4 \mathrm{H}, \mathrm{bs}) ; 0.72(2 \mathrm{H}, \mathrm{m}) ; 1.49-1.54(144 \mathrm{H}, \mathrm{m}) ; 2.28$ $(4 \mathrm{H}, \mathrm{s}) ; 2.40(2 \mathrm{H}, \mathrm{m}) ; 2.69(4 \mathrm{H}, \mathrm{s}) ; 2.80(4 \mathrm{H}, \mathrm{s}) ; 3.66(4 \mathrm{H}, \mathrm{s}) ; 3.91(18 \mathrm{H}, \mathrm{s}) ; 4.58(4 \mathrm{H}, \mathrm{s}) ; 7.80(4 \mathrm{H}, \mathrm{t}$, $\mathrm{J}=1.6 \mathrm{~Hz}) ; 7.95(4 \mathrm{H}, \mathrm{s}) ; 7.98(8 \mathrm{H}, \mathrm{s}) ; 8.08(8 \mathrm{H}, \mathrm{s}) ; 8.59(4 \mathrm{H}, \mathrm{s}) ; 8.76(4 \mathrm{H}, \mathrm{s}) ; 8.97$ (4H, d, J=4.9 Hz); $9.03(4 \mathrm{H}, \mathrm{d}, \mathrm{J}=4.9 \mathrm{~Hz})$.

Bis-porphyrin adduct 12: Porphyrin block 8 (68 mg, $52 \mu \mathrm{mol})$ along with bis-epoxide 11 (10 mg, 25 $\mu \mathrm{mol})$ were dissolved in THF $(1 \mathrm{~mL})$ and the solution heated in a sealed tube in the dark at $140^{\circ} \mathrm{C}$ for 2 days. The solution was taken to dryness and the resulting material purified by column chromatography (silica) eluting with DCM/petroleum spirit (1:1) to give recovered 8 (19 mg) followed by $\mathrm{CHCl}_{3} / \mathrm{THF}$ 
(1\%) to yield 12 (19 mg, 34\% based on porphyrin consumed). Recrystalised from DCM/MeOH. M.p. $>350^{\circ} \mathrm{C}$. HR-ESMS calculated for $\mathrm{C}_{201} \mathrm{H}_{224} \mathrm{~N}_{16} \mathrm{O}_{14}(\mathrm{M}+2 \mathrm{H})^{2+}$ 1512.887; observed 1512.889; ${ }^{1} \mathrm{H}-\mathrm{NMR}$ $\left(\mathrm{CDCl}_{3}\right): \delta-2.40(4 \mathrm{H}, \mathrm{bs}) ; 0.71(2 \mathrm{H}, \mathrm{d}, \mathrm{J}=11.7 \mathrm{~Hz}) ; 1.49-1.53(144 \mathrm{H}, \mathrm{m}) ; 1.97(2 \mathrm{H}, \mathrm{bs}) ; 2.04(6 \mathrm{H}, \mathrm{bs})$; $2.28(5 \mathrm{H}, \mathrm{m}) ; 2.83(4 \mathrm{H}, \mathrm{s}) ; 3.69(4 \mathrm{H}, \mathrm{s}) ; 3.91(12 \mathrm{H}, \mathrm{s}) ; 7.80(4 \mathrm{H}, \mathrm{t}, \mathrm{J}=1.6 \mathrm{~Hz}) ; 7.96(4 \mathrm{H}, \mathrm{t}, \mathrm{J}=1.6 \mathrm{~Hz})$; $7.99(8 \mathrm{H}, \mathrm{d}, \mathrm{J}=1.6 \mathrm{~Hz}) ; 8.09(8 \mathrm{H}, \mathrm{d}, \mathrm{J}=1.6 \mathrm{~Hz}) ; 8.59(4 \mathrm{H}, \mathrm{s}) ; 8.77$ (4H, s); 8.97 (4H, d, J=4.9 Hz); 9.05 $(4 \mathrm{H}, \mathrm{d}, \mathrm{J}=4.9 \mathrm{~Hz})$.

Bis-porphyrin adduct 14: Porphyrin block 8 (90 mg, $69 \mu \mathrm{mol})$ along with bis-epoxide 13 (15 mg, 25 $\mu \mathrm{mol})$ were dissolved in THF $(500 \mu \mathrm{L})$ and the solution heated at $160^{\circ} \mathrm{C}$ in a sealed tube for 2 days. The solution was taken to dryness and the resultant solid purified by column chromatography (silica) eluting with DCM/petroleum spirit (1:1) to give residual block 8 (17 mg) followed by $\mathrm{CHCl}_{3} / \mathrm{EtOAc}$ (5\%) to yield 14 (69 mg, 62\%). Recrystalised from DCM/MeOH. M.p. $>350^{\circ} \mathrm{C}$. HR-ESMS calculated for $\mathrm{C}_{210} \mathrm{H}_{232} \mathrm{~N}_{16} \mathrm{O}_{14}(\mathrm{M}+2 \mathrm{H})^{2+} 1602.9078$; observed 1602.9084; ${ }^{1} \mathrm{H}-\mathrm{NMR}\left(\mathrm{CDCl}_{3}\right): \delta-2.40(4 \mathrm{H}, \mathrm{bs})$; $0.72(2 \mathrm{H}, \mathrm{d}, \mathrm{J}=10.7 \mathrm{~Hz}) ; 1.49-1.55(144 \mathrm{H}, \mathrm{m}) ; 2.23(4 \mathrm{H}, \mathrm{s}) ; 2.31(2 \mathrm{H}, \mathrm{d}, \mathrm{J}=10.7 \mathrm{~Hz}) ; 2.38(4 \mathrm{H}, \mathrm{s}) ; 2.82$ $(4 \mathrm{H}, \mathrm{s}) ; 2.84(4 \mathrm{H}, \mathrm{s}) ; 2.88(2 \mathrm{H}, \mathrm{s}) ; 3.69(4 \mathrm{H}, \mathrm{s}) ; 3.80(6 \mathrm{H}, \mathrm{s}) ; 3.93(12 \mathrm{H}, \mathrm{s}) ; 7.80(4 \mathrm{H}, \mathrm{s}) ; 7.96(4 \mathrm{H}, \mathrm{s})$; $7.99(8 \mathrm{H}, \mathrm{s}) ; 8.09(8 \mathrm{H}, \mathrm{s}) ; 8.59(4 \mathrm{H}, \mathrm{s}) ; 8.77$ (4H, s); 8.97 (4H, d, J=4.7 Hz); 9.04 (4H, d, J=4.7 Hz).

\section{References and Notes}

1. Pullerits, T.; Sundström, V., Photosynthetic Light-Harvesting Pigment-Protein Complexes: Toward Understanding How and Why, Acc. Chem. Res., 1996, 29, 381-389; McDermott, G.; Prince, S. M.; Freer, A. A.; Hawthornwaite-Lawless, A. M.; Papiz, M. Z.; Cogdell, R. J.; Isaacs, N. W., Crystal structure of an integral membrane light-harvesting complex from photosynthetic bacteria, Nature, 1995, 374, 517-521.

2. For recent leading references see: Nakano, A.; Yamazaki, T.; Nishimura, Y.; Yamazaki, I.; Osuka, A., Three-Dimensionally Arranged Windmill and Grid Porphyrin Arrays by Ag-Promoted mesomeso Block Oligomerization, Chem. Eur. J., 2000, 6, 3254-3271; Vicente, M. G. H.; Jaquinod, L.; Smith, K. M., Oligomeric porphyrin arrays, Chem. Commun, 1999, 1771-1782.

3. For an excellent review see: Chambron, J-C.; Heitz, V.; Sauvage, J-P., Noncovalent multiporphyrin assemblies, Porphyrin Handbook, 1-42, vol. 6, 2000, Ed Kadish, K. M.; Smith, K. M.; Guilard, R.

4. Warrener, R. N.; Johnston, M. R.; Gunter, M. J., Preparation of New Porphyrin BLOCKs and their Application to the Synthesis of Spacer and Cavity Ribbon Structures, Synlett, 1998, 593-595.

5. Johnston, M. R.; Gunter, M. J.; Warrener R. N., Templated formation of multiporphyrin assemblies resembling a molecular universal joint, Chem. Commun., 1998, 2739-2740.

6. Warrener, R. N.; Schultz, A. C.; Johnston, M. R.; Gunter, M. J., New Porphyrin 4 $\pi$-Cycloaddition Reagents and their use in the Preparation of Porphyrin-(Rigid Spacer)-1,10-Phenanthrolines in which Geometric 'Tuning' of the Chromophores is a Feature, J. Org. Chem., 1999, 64, 4218-4219.

7. Warrener, R. N.; Schultz, A. C.; Butler, D. N.; Wang, S.; Mahadevan, I. B.; Russell, R. A., A New Building BIOCK Technique Based on Cycloaddition Chemistry for the Regiospecific Linking of Alicyclic Sub-units as a Route to Large, Custom-Functionalised Structures, Chem. Commun., 1997, 1023-1024; Butler, D. N.; Malpass, J. R.; Margetic, D.; Russell, R. A.; Sun, G.; Warrener, R. N., A 
1,3-Dipolar Cycloaddition Route to 7-Azanorbornanes: Application to the Synthesis of syn-Facial $N$-Bridged Polynorbornanes, Synlett, 1998, 588-589.

8. Crossley M. J.; Govenlock L. J.; Prashar J. K., Synthesis of Porphyrin-2,3,12,13- and -2,3,7,8tetrones: Building Blocks for the Synthesis of Extended Porphyrin Arrays, J. Chem. Soc., Chem. Commun., 1995, 2379-2380; Crossley M. J.; Burn P. L., An Approach to Porphyrin-based Molecular Wires: Synthesis of a Bis(porphyrin)tetraone and its Conversion to a Linearly Conjugated Tetrakisporphyrin System, J. Chem. Soc., Chem. Commun., 1991, 1569-1571.

9. Johnston, M. R.; Warrener, R. N. manuscript in preparation.

10. Warrener, R. N.; Margetic, D.; Amarasekara, A. S.; Russell, R. A., The synthesis of functionalised cavity structures via 1,3-dipolar cycloaddition of angle-shaped alkenes to curved norbornene framed dipoles, Org. Lett., 1999, 2, 203-206.

11. Martin, H-D.; Schiwek, H-J.; Spanget-Larsen, J.; Gleiter, R., Synthesis, Spectroscopic Properties and Transannular Interactions of Tricyclic 1,2-Cyclobutanediones, Chem. Ber., 1978, 111, 25572562; Albert, B.; Heller, C.; Iden, R.; Martin, G.; Martin, H-D.; Mayer, B.; Oftring, A., Design and Synthesis of $\alpha$-Diketones. The Cyclobutane-1,2-dione Chromophore: Synthesis, Dienophilic Reactivity and Electronic Properties of Cyclobutenedione and Polycyclic Cyclobutanediones, Israel J. Chem., 1985, 25, 74-83.

12. Molecular modeling was carried out using SPARTAN v5.0.3 (Wavefunction Inc.) on an Silicon Graphics Indigo $^{2}$ workstation. Minimisations were done without peripheral substituents such as aromatic rings or ester groups which have no bearing on the geometric outcome of the calculation.

13. Margetic, D. M., Warrener. R. N., unpublished results.

14. Warrener, R. N., Margetic, D. M., Foley, P. J., Butler, D. N., Winling, A., Beales, K., A., Russell, R. A., syn-Facial hetero-bridged [n]polynorbornanes: a new class of polarofacial framework molecules composed of fused 7-oxa- and 7-azanorbornanes, Tetrahedron, 2001, in press.

15. Margetic, D., Johnston, M. R., Tiekink, E. R. T., Warrener, R. N., Synthesis and Modelling of Novel Rigid Rods derived from a Simple pentacyclic bis-norbornene, Tetrahedron Lett., 1998, 39, 5277-5280.

Sample availability: Available from the author.

(C) 2001 by MDPI (http://www.mdpi.org). Reproduction is permitted for non-commercial purposes 